\title{
Value of Brachytherapy as Part of Interdisciplinary Therapeutic Concepts for Solid Tumor Lesions - Brachytherapeutic Options and Spectrum of Treatment Results at the Center of Radiology (Department of Radiotherapy - University Hospital of Magdeburg)
}

\author{
Hass P ${ }^{*}$, Meyer $F^{2}$, Ricke J ${ }^{3}$, Mohnike $\mathrm{K}^{3}$, \\ Eggemann $\mathbf{H}^{4}$, Seidensticker $\mathrm{M}^{3}$, Arens $\mathrm{C}^{5}$, Walke \\ $\mathbf{M}^{6}$ and Gademann $\mathbf{H}^{6}$ \\ ${ }^{1}$ Department of Radiation Therapy, University Hospital, \\ Magdeburg, Germany \\ ${ }^{2}$ Department of General, Abdominal and Vascular \\ Surgery, University Hospital, Magdeburg, Germany \\ ${ }^{3}$ Department of Radiology and Nuclear Medicine, \\ University Hospital, Magdeburg, Germany \\ ${ }^{4}$ Department of Gynecology and Obstetrics, University \\ Hospital, Magdeburg, Germany \\ ${ }^{5}$ Department of Otorhinolarngology, University Hospital, \\ Magdeburg, Germany \\ ${ }^{6}$ University Hospital at Magdeburg, Magdeburg; Germany \\ *Correspondling author: P Hass, Department of \\ Radiation Therapy, University Hospital, Magdeburg, \\ Germany
}

Received: November 14, 2016; Accepted: December 22, 2016; Published: December 24, 2016

\begin{abstract}
As in many other medical disciplines, a substantial change of paradigms in oncology and oncotherapy can be observed. In particular, for the treatment of solid tumor lesions the former rather rigid approach to differentiate between curative (no detection of distant metastases) and palliative intention (including systemic advancement of tumor disease) has been increasingly overcome. The concept of oligometastases has been getting more and more attention. Oligometastatic status can be classified if in first diagnosis or in follow-up investigation for tumor staging only a few distant metastases are found. According to the former guidelines, this might only lead to initiation of a palliative treatment, in the majority of cases to a systemic type of therapy! Interestingly, there has been substantial evidence that local ablation of the small number of filiae can favorably influence quality of life (the main intent of "palliative care" according to the definition by WHO) and prognosis. However, there are no predictive markers yet such as laboratory parameters, which allow to assess prognosis of a certain tumor stage / disease including oligometastases.
\end{abstract}

Surgical resection was and is the gold standard of local ablation but only a certain percentage of patients with oligometastases can be approached with surgical intervention since several of them areunresectable from a technical or inoperable from an anesthesiological point of view. In addition to surgical ablation, there have been a number of non- or minimally invasive techniques available such as thermo-, chemo- and radioablading procedures.

This review aims at Brachytherapy (BT) as radioablating method, its indications as part of curative concepts, the possible treatment spectrum shown in detail at the University Hospital of Magdeburg (Germany), and, in particular, indicating what is feasible and achievable from a qualitative and quantitative point of view. Finally, exemplary and representative cases document the potential benefit in radioablation of metastases.

Keywords: Brachytherapy; Radiation Therapy; Interstitial Brachytherapy (IBT); Organs at Risk (OAR); Oncological profile of diagnoses

\section{Introduction}

Immediately after discovery of X-rays by Röntgen [1] as well as of radioactivity and radium by Becquerel as well as Madame Curie and her husband [2-4]. Freund reported the first medical use of X-rays in a benign dermatological disease [5]

Through the following years, radiotherapy began to be established as one of the main treatment principles in malignant tumor disease [6-10]. From the beginning, two basic strategies were pursued and further developed:

1. Radiotherapy with X-rays from external site via a greater distance through the skin (percutaneous radiotherapy with great operating range, the so-called "external beam radiotherapy"=EBRT), and

2. Contact radiation by means of radioactive sources (radiation with short operating range, therefore "brachytherapy" derived from the Greek word ßpaxúc for short).

BT, which is the main focus of this overview, can be, therefore, considered a type of radiotherapy, which has been used for more than 100 years [11-14].

In contrast to the percutaneous photon-based radiation generated by X-ray tube or linear accelerator, the today's BTis based on photons generated by radioactive gamma decay(since generated
Austin J Radiat Oncol \& Cancer - Volume 2 Issue 2 - 2016 ISSN : 2471-0385 | www.austinpublishing group.com Hass et al. () All rights are reserved 
by radioactive decay, it is called gamma radiation). This radiation has only a short operating range due to the significantly lower amount of energy providing the advantage that during therapeutic procedure, the surrounding organs (called "organs at risk"[OAR]) can be much better preserved than by a percutaneous radiation mode. On the other hand, BT requires a spatially not much extended rather close distance between radiation source and tumor lesion. To realize this, either special applicators (intraluminal BT), catheters, tubes or hole needles (interstitial BT) needs to be placed or inserted:

- Within or near the tumor lesion (definitive or primary radiotherapy),

- Into a postoperative (former) tumor bed, in existing (hole) spaces/lumens (e.g., esophagus, Bronchus, cervix) (or)

- In case of superficial mucosa or skin tumors, into moulages, which are adhered to the tumor surface?

Via the devices, radioactive source is transferred to or at the tumor lesion using After Loading( $\mathrm{AL}$ ) procedure after previous 3D-based imaging and precise calculation of the appropriate dos(ag) e. Depending on the dose rate per time, "Low-Dose-Rate" (LDR), "Medium-Dose-Rate" (MDR) or "High-Dose-Rate" (HDR) BT is distinguished. According to this, the duration of the radiation is different, e.g., in "low-risk" prostate cancer encapsulated iodine or palladium seeds can be used as part of a LDR-BT, which provides the effective cumulative dose within only three months. In contrast, HDR-BT takes only several minutes.

Both strategies of radiation (EBRT and BT) have become clinical standard in the mean time. However, BT is used only for a restricted spectrum of indications in the majority of centres, in particular, in gynecological tumor lesions (carcinoma of the vagina, of the endometrium and cervix uteri as well as breast cancer, in the latter case as boost or in cases of local tumor recurrency) and prostate cancer. In addition, BT is also considered a potential standard procedure in superficial end luminal tumor lesions of the bronchial system or the esophagus.

Last but not least, brachytherapy is also part of the therapeutic spectrum for tumor lesions of otorhinolaryngology at several institutions of radiotherapy.

Without dispute, there is no sustainable therapeutic result achievable with no complete resection of the primary tumor lesion or even metastases, and derived from this, surgical resection has a great value in this concept.

In various tumor entities such as cancer of the pharynx, cervix, prostate and anus, it has been shown [15-18] that radiation and a combined radio-/chemotherapy can be considered an equivalent treatment alternative for curation of locally advanced nonmetastasized tumor stages.

In case of

\section{- Oligometastasized tumor stage (or)}

- Local recurrence of the tumor lesion,

Local clearance of tumor growth can also result in a potential improvement of overall tumor prognosis in addition to a mitigation of tumor-associated symptoms.

For patients who are inoperable and unrespectable due to various reasons, numerous minimally invasive tumor-abladingtherapy modes have been introduced and established in clinical practice [1921 , which broaden the spectrum of available options to treat cancer patients. In this context, Radio Frequence Ablation (RFA) [22-25] as thermoablative or interstitial brachytherapy (iBT) [26-30] as radioablative procedure need to be mentioned.

Taken together, beside oncosurgery as the undisputable gold standard for the treatment of solid tumor lesions in numerous tumor diseases there are effective alternatives and additive procedures.

The common aim is to achieve local tumor control but alternative treatment strategies are mainly used if surgical intervention is not the best choice due to various reasons.

However, there has been no broad consensus yet since for the majority of tumor diseases, prospective studies comparing the various alternative or additive approaches are rather rare.

Therefore, on one hand the novel minimally invasive measures need to be discussed in the interdisciplinary tumor board sessions and to be used adequately according to their therapeutic potential (in particular, if tumor resection is not a reasonable choice) and on the other hand, studies need to be initiated comparing the various therapeutic procedures to gain for appropriate evidence.

By means of modern tomographic imaging, it has become possible to reach almost each tumor lesion by means of a minimally invasive approach using diverse applicators such as catheters or hole needles and, thus, to put brachytherapy into effect.

In particular, for pulmonary and hepatic metastases of colorectal carcinomas and for hepatocellular carcinoma (HCC), effectiveness by radiotherapy modes has been detected with regard to local tumor control and overall tumor prognosis [31-34].

Most likely, indication profile will be extended due to ongoing clinical phase-II studies, e.g.,

-Use of iBT in renal cancer,

-Combination of radiotherapy with systemic therapy in cholangiocarcinoma (or)

-Feasibility and effectivity of a hypo fractionated brachytherapy.

Are investigated (EUDRA-CT 2011-002839-25, EUDRA-CT 2008-001316-21, EUDRA-CT 2009-015419-42).

The aim of the manuscript is based on the overall positive experiences and the recent dynamic development of modern BT to provide an update on the today's options of this very specific and novel mode of tumor therapy. In particular, it is shown in which indications BT (spectrum of diagnoses) can be reasonably considered in addition to surgical and locally ablative procedures as well as novel concepts can be put into effect at the University Hospital of Magdeburg (Germany) in daily clinical practice. In detail,

1. It is described which specific procedures of BT (methodological profile) are used,

2. It is shown what case numbers can be achieved currently, 
Table 1: Chronological overview of representative studies on brachytherapy.

\begin{tabular}{|c|c|c|}
\hline AUTHOR & Title ofpublication & Bibliograficdata \\
\hline ICRU & Dose and volume specification for reporting intracavitary therapy in gynecology. & $\begin{array}{l}\text { ICRU Report } 38 \text { 1985; Washington: International } \\
\text { Commission on Radiation Units and } \\
\text { measurements }\end{array}$ \\
\hline $\begin{array}{l}\text { Thomas DS, Nauta RJ, } \\
\text { Rodgers JE et al. }\end{array}$ & $\begin{array}{l}\text { Intraoperative high-dose rate interstitial irradiation of hepatic metastases from } \\
\text { colorectal carcinoma. }\end{array}$ & Cancer 1993; 71: 1977-1981 \\
\hline $\begin{array}{l}\text { Takehiro I, Toshihiko I, Teruki } \\
\text { T et al. }\end{array}$ & $\begin{array}{l}\text { Phase III trial of high and low dose rate interstitial radiotherapy for early oral } \\
\text { tongue cancer. }\end{array}$ & Int J Radiat Oncol Biol Phys 1996; 36: 1201-1204 \\
\hline ICRU. & Dose and volume specification for reporting interstitial therapy. & $\begin{array}{l}\text { ICRU Report 581997, Bethesda: International } \\
\text { Commission on Radiation Units and } \\
\text { measurements }\end{array}$ \\
\hline Wambersie A, Battermann JJ. & Dose specification and reporting: the ICRU recommendations. & $\begin{array}{c}\text { Joslin CAF, Flynn A, Hall EJ (eds). Principles and } \\
\text { practice of brachytherapy 2001. London: Arnold, } \\
81-102\end{array}$ \\
\hline $\begin{array}{l}\text { Ricke J, Wust P, Stohlmann } \\
\text { A et al. }\end{array}$ & $\begin{array}{l}\text { CT guided interstitial brachytherapy of liver malignancies alone or in combination } \\
\text { with thermal ablation: Phase I-II results of a novel technique. }\end{array}$ & Int J Radiat Oncol Bio Phys 2004; 58:1496-1505 \\
\hline Kraus-Tiefenbacher et al. & $\begin{array}{l}\text { Long-term toxicity of an intraoperative radiotherapy boost using low energy } \\
\text { x-rays during breast-conserving surgery. }\end{array}$ & Int J Radiat Oncol Biol Phys 2006; 66: 377-381 \\
\hline $\begin{array}{l}\text { Wieners G, Mohnike K, Peter } \\
\text { N et al. }\end{array}$ & $\begin{array}{l}\text { Treatment of hepatic metastases of breast cancer with CT-guided interstitiell } \\
\text { brachytherapy - A phase II-study. }\end{array}$ & RadiotherOncol2011; 100: 314-319 \\
\hline Grimm $P$ et al. & $\begin{array}{l}\text { Comparative analysis of prostate-specific antigen free survival outcomes for } \\
\text { patients with low, intermediate and high risk prostate cancer treatment by radical } \\
\text { therapy. Results from the Prostata Cancer Results Study Group. }\end{array}$ & BJU Int 2012; 109 (suppl): 22-29 \\
\hline Davis BJ et al. & $\begin{array}{c}\text { American Brachytherapy Society consensus guidelines for transrectal ultrasound } \\
\text { guided permanent prostate brachytherapy. }\end{array}$ & Brachytherapy 2012; 11: 6-19 \\
\hline $\begin{array}{l}\text { Tselis N, Chatzikonstantinou } \\
\text { G, Kolotas C et al. }\end{array}$ & $\begin{array}{l}\text { Computed tomography-guided interstitial high dose rate brachytherapy for } \\
\text { centrally located liver tumours: a single institution study. }\end{array}$ & EurRadiol 2013; 23: 2264-2270 \\
\hline
\end{tabular}

3. Practical experiences are discussed obtained in clinical routes. studies, (and)

4. Selective references from the literature are provided, (as well as)

5. Representative cases are reported.

\section{General Treatment-associated Data}

For an adequate, case-specific decision-making with regard to an appropriate indication and competent realization of the majority of BT, a confident interdisciplinary collaboration is basically required. In particular, this is important for the interstitial application (iBT), e.g.

1. Under ultrasound, CT or MRT guidance tumor lesion is larded with BT catheters (or)

2. Applicators are inserted into whole spaces under CT or ultrasound guidance (or)

3. After tumor debulking or postoperative imaging of the residual tumor lesion, catheters are placed within the tumor bed.

The conceptual idea is to

- achieve a maximally possible, i.e., acceptable tumor-damaging radiation (dose) but,

Simultaneously,

- minimize radiation-induced side effects (e.g., irritable bowel syndrome, skin reaction etc.)

With curative, adjuvant, additive or palliative intention as well as the most promising fractionation modus (one session up to $30 \mathrm{~Gy}$, fractionation with 2 radiation sessions per day up to an overall dosage of 30-36Gy) by placement of local radiation sources via various access

The interdisciplinary teams comprise radio oncologists, general and abdominal surgeons, otorhinolaryngologists, oral and maxillofacial surgeons, gastroenterologists, gynecologists, pulmologists and, in particular, interventional radiologists.

\section{Overall Survey of Treatment Data}

From04/2006 to $12 / 2013$, the number of BT increased steadily until 2009 and since then, it has been consolidated.

On average, 330-350 patients per year are currently treated, several of them with oligometastasized status are treated at various tumor sites resulting in a number of procedures (with regard to the treated tumor manifestation sites) of approximately 450.

The mean age of patients was 63.94 (range, 15-89) years; sex ratio (f: $\mathrm{m}$ ) of iBT patients was $38.4: 61.6 \%$ (overall including gynecological BT, 55.0:45.0\%)

Out of the 2,278 patients treated until 12/2013,

- 56\% underwent iBT of the liver, lung etc.

- 36\% were transferred from gynecological departments for an intraluminal, partially also additional Interstitial BT of the genitals,

- $8 \%$ were treated with interstitial BT or via moulagesat tumor sites of otorhinolaryngology, with Intraluminal (endobronchial, esophageal, anal or endobiliary) BT (and)

- $1 \%$ underwent intraoperative radiation using the INTRABEAM device (Carl ZeissMeditec AG, Jena, Germany).

A substantial proportion of the iBT patients underwent multiple BT sessions at various tumor manifestation sites, finally resulting in a number of single applications of 3,117. 
The comparison with data from the literature is almost not possible since the proportion of iBT for the treatment of metastases within various organs (lung, liver, kidney etc.) at the reporting institution is extraordinarily high.

The usually provided "standard"BT comprises (as mentioned above) mainly

- Prostate-associated HDR-BT or seed implantations,

-Gynecological and intraluminal applications (and)

- Interstitial treatment of tumor recurrency lesions, e.g., of breast cancer (Table 1).

\section{Medical Discipline and Diagnosis-specific Treatment Experiences}

\section{Gynecology}

Gynecology belongs to the classical field of this mode of radiotherapy to use BT in malignant gynecological diseases. Dominici is one of the pioneers in the field who worked first with radium capsulas implanted intrauterinely in endometrial cancer [35]. Subsequently, intracervical and intrauterine applicators were developed and implanted [36-40].

Today, adjuvant vaginal BT depending on tumor stage according to FIGO classification alone or in combination with EBRT (BT, in particular, to reduce the risk for recurrent tumor growth at the vaginal stump)in endometrial cancer[41-43] as well as intracervical/ interstitial application as part of definitive radiochemotherapy of cervical cancer $[44,45]$ belong to standardized treatment protocols.

In addition, BT alone or in combination with percutaneous radiation and simultaneous chemotherapy can also be used, e.g.,

- In primary tumor lesions of the vagina [46-48] (or)

- In vulvar cancer for a preoperative or adjuvant therapeutic setting oras definitive treatment [49-51] predominantly with curative intention.

Through the investigation period, overall

- 474 patients with gynecological tumor lesions (except breast cancer) with 1,626 BT fractions were treated,

${ }^{*}$ out of them, 85 patients with primary, inoperable cervical cancer,

- 358 endometrial cancer patients (and)

- 31 cases with vaginal or vulvar cancer or recurrent tumor growth of uterine neoplasms.

Head-and-neck tumor lesions

Tumor lesions of the head and neck belong - beside gynecological neoplasms - to the first diagnoses, in which BT was used. First, patients were treated with contac BT using radium capsulasor individual moulages, later on due to the development of radiumconsisting needles (which were larded within the tumor bed) with interstitial BT [52,53]. iridium.

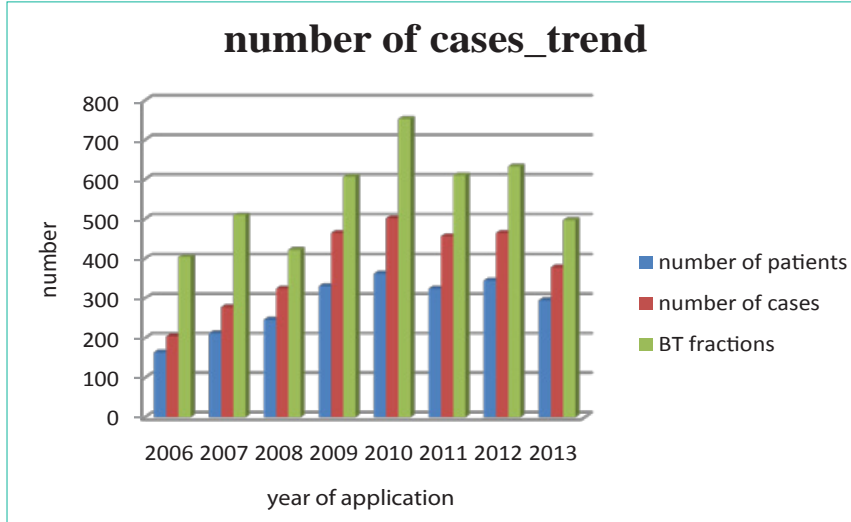

Figure 1: BT procedures according to No. of patients, cases and BT fractions. Overall treatment numbers for all brachytherapies from 2006-2013.

\section{number of treatments 2006-2013}

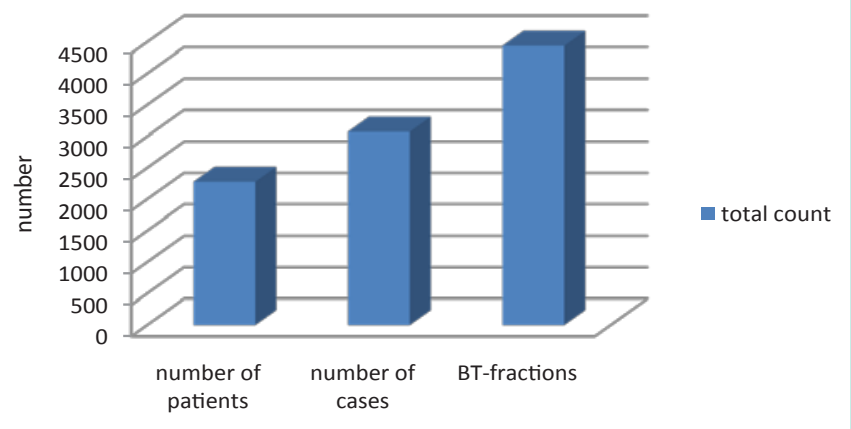

Figure 2: No. of performed BT in total.

Overall treatment numbers for all brachytherapies from 2006-2013.

Tumor lesions of the head and neck can be considered a heterogeneous group of patients; therefore, a uniform superordinated treatment concept cannot be easily defined. Currently, there is only a German S3-guideline existing for floor-of-mouth cancer [55], however, there has been a study-based consensus with regard to the role of percutaneous radio-/radiochemotherapy with adjuvant and definitive intention [56-58].

In contrast, a possible interstitial BT without external beam radiation therapy (EBRT) or boostering is frequently not discussed or offered though BT has a substantial value based on several studies [59] with regard to local tumor control and improvement of the overall prognosis [60]. The GEC-ESTRO group (Groupe Européen de Curiethérapie and the European Society for Radiotherapy \&Oncology) recommends, therefore, using BT at head and neck [61].

Basically, BT can be used in the following situations:

1. As alternative for surgical resection of locally restricted $\mathrm{T} 1 / 2$ tumor lesions, in particular, at the lips, cheeks and oral cavity [62-64],

2. As addition to percutaneous radiation providing a local dosage escalation in advanced inoperable tumor lesions or after R1 resections and lack of a promising option for repeated resection [65] (and)

3. In recurrent tumor growth at the local tumor site or within lymph nodes and in patients pretreated with 


\section{BT-fractions 2006-2013}
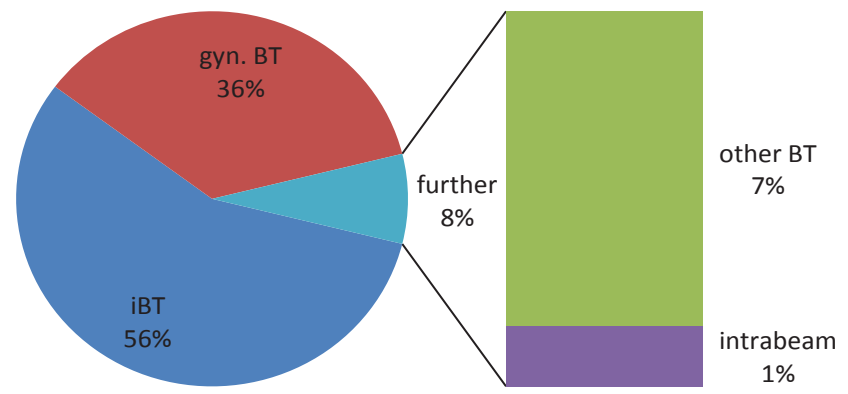

$1 \%$

Figure 3: Relative portion of the applied BT fractions (tomography-guided iBT, gynecological BT, further [intraoperative, intraluminale, contact] BT and IORT of the tumor bed with\#, INTRABEAM device).

Overall treatment numbers for all brachytherapies from 2006-2013.

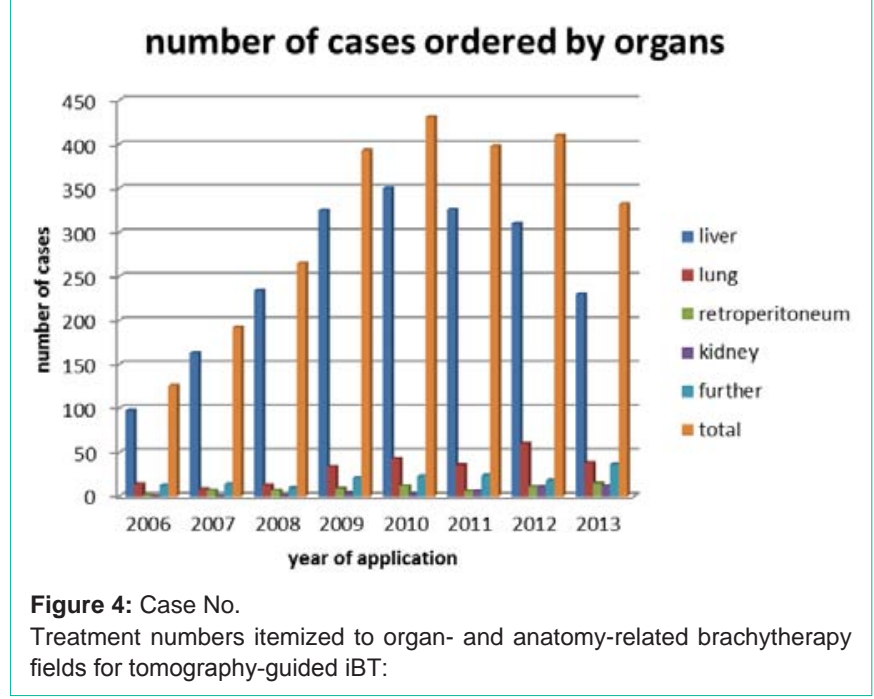

Percutaneous radiotherapy [66-70].

At the University Hospital of Magdeburg (Germany), locally restricted tumor lesions are usually resected, boosting is used via percutaneous access route due to the available modern radiotherapy techniques (e.g., tomotherapy, intensity-modulated radiotherapy=IMRT).

Derived from this, HDR-BT has been predominantly offered to and used in cases with recurrent tumor growth or with palliative intention as well as with previous radiotherapy. Overall, 18 patients were treated from 06/2006 to 12/2013 (Figure 1-7),

-5 after patient-made production of individual moulages,

-13 after surgical intervention aiming for tumor-debulking and in unrespectable tumor growth, respectively,

With interstitial BT. The doses varied from 20 to $36 \mathrm{Gywith}$ single doses of 2.5-3Gytwice a day and a minimal interruption of 6 hours between the single fractions.

Brachytherapy in intraluminal tumor lesions

Intraluminal BT applications may reasonably add multimodal

\section{Number of patients ordered by organs}

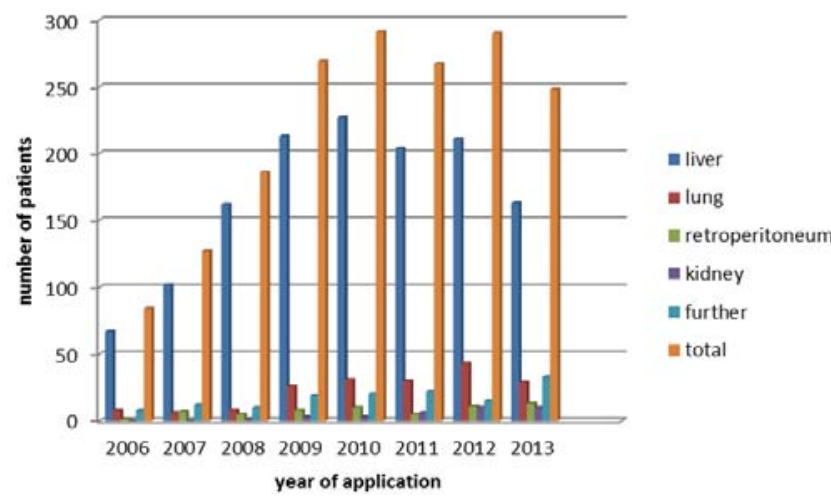

Figure 5: Patient No

Treatment numbers itemized to organ- and anatomy-related brachytherapy fields for tomography-guided iBT:

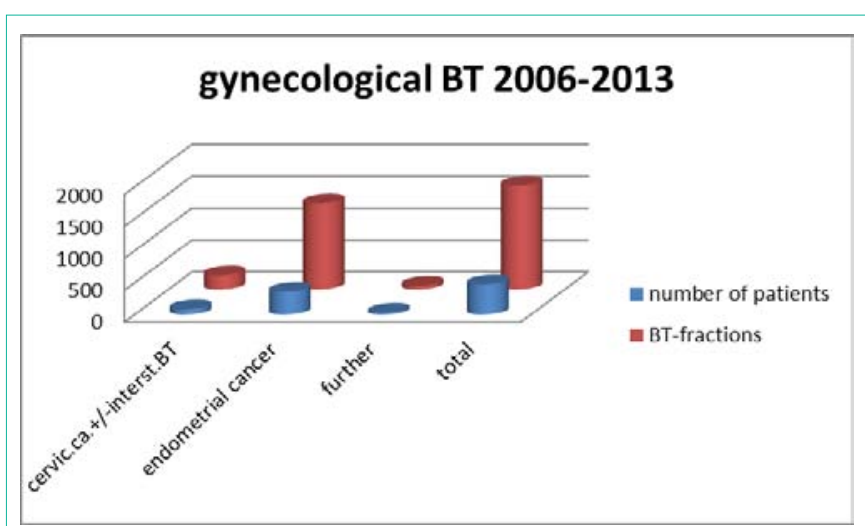

Figure 6: Distribution. Gynecolocical brachytherapy.

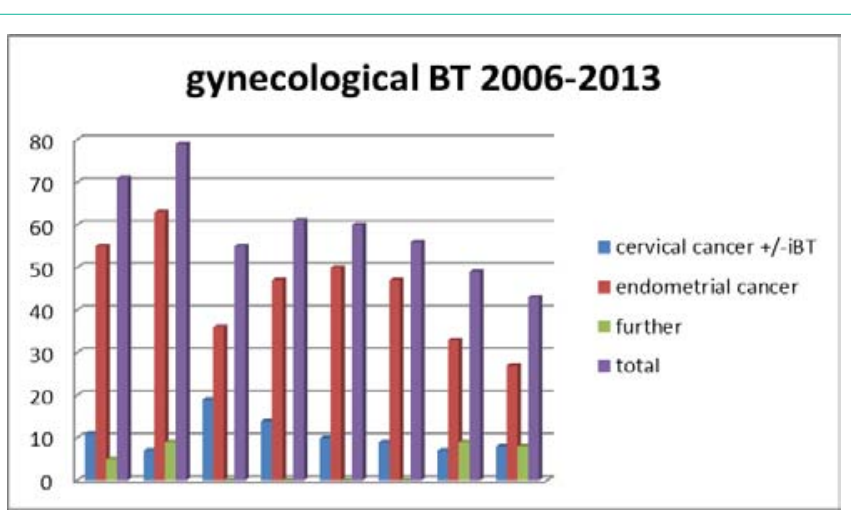

Figure 7: Development of case No. Gynecological brachytherapy.

treatment concepts with curative or palliative intention [71,72]. In the following tumor sites, BT has been proven:

- Bronchial [73-75],

- Esophageal [76, 77],

- Biliary[78,79] (and)

- Anal [80].

BT plays, in particular, an additional role to the 


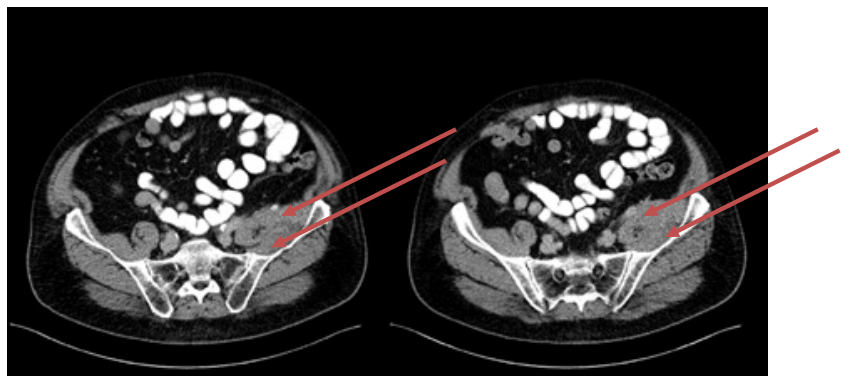

Figure 8: CT transversal scan: Tumorous enrichment of soft tissue marked with arrows- casus 1

- Primary surgical approach,

- Percutaneous radiation,

- Combination with palliative chemotherapy, and

- Palliative intention in pretreated patients with percutaneous radiotherapy.

At the reporting institution, overall 21 patients underwent BT at the tumor sites as listed above from 2006 to 2013:

- The largest proportion comprised patients with recurent tumor growth of esophageal cancer,

- 4 cases with locally restricted but despite this unrespectable cholangiocarcinoma (and)

- The remaining cases were successfully treated with palliative intention aiming for local tumo Control.

Interstitial brachytherapy (iBT) for treatment of local tumor lesions and metastases.

In addition to the described indications, metastases within parenchymatous organs (liver, lung, and kidney) or even soft tissue and lymph node metastases are suitable for iBT. In detail, needles or BT catheters are precisely inserted - either intraoperatively or under CT- or MRT-based fluoroscopy guidance - into malignant tumor masses. Using this approach, lower numbers of thoracic/pulmonary, hepatic or abdominal metastases but also primary livertumors or soft tissue sarcomas can be treated.

Feasibility, safety and benefit of this minimally invasive type of radiation has been proven by numerous retro- and prospective studies and analyses in the mean time $[26,31,81,82]$, which thus occupies an established place in the reporting department.

This has become possible by the close collaboration with interventional radiologists and all the transfering oncological disciplines in medicine, in particular, with abdominal surgery.

Primary aim was to achieve local symptom control by radiationinduced cytoreduction with palliative intention at the beginning [26] but the study results showed that in numerous cases, a sustainable local control sometime even an improvement of the overall prognosis became possible.

In the phase-II study by Ricke et al. [83], local controlrate after iBT of overall 73 patients (subdivided into three various groups of doses [one-time doses per group: 15, 20 or 25 Gy]) with 199

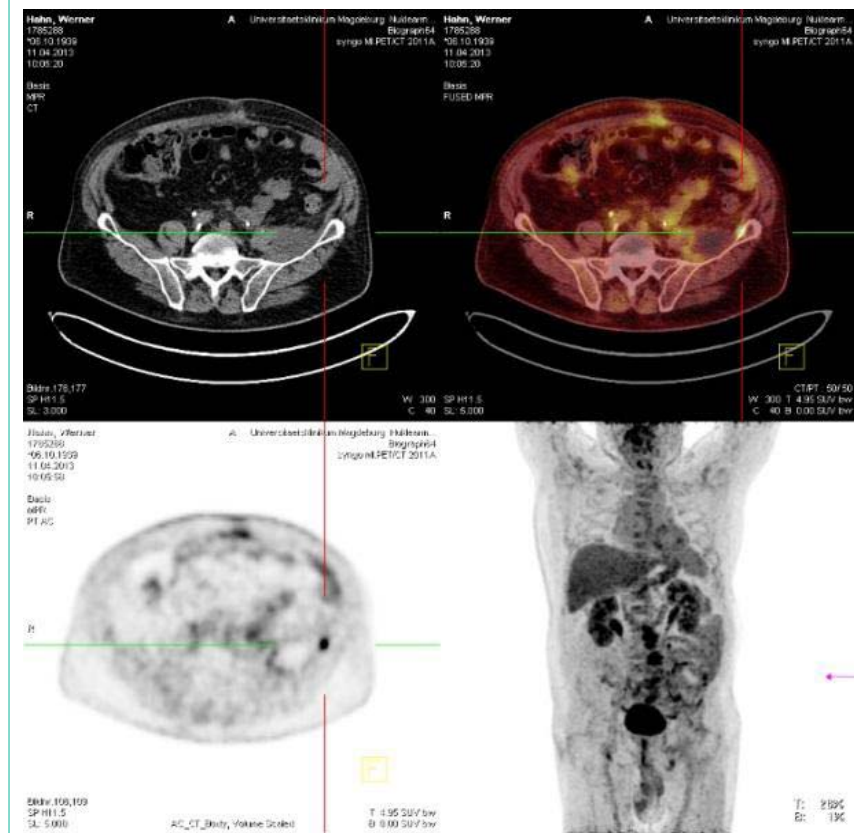

Figure 9: PET-CT: Positive residual tumor tissue after debulking - casus 1.

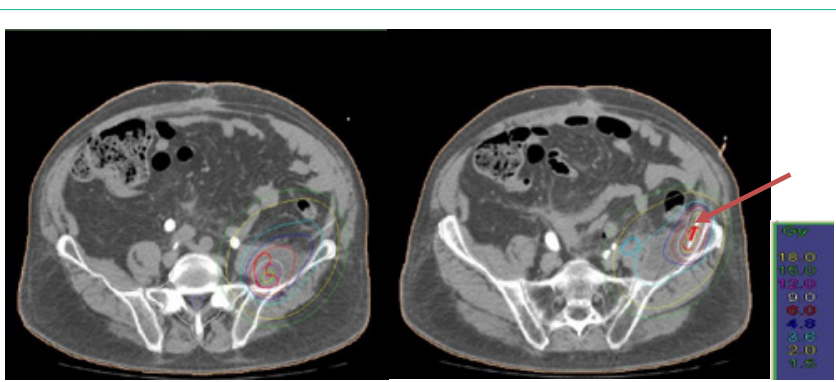

Figure 10: CT transversal scan: Tumor-surrounding isodoses (red; left panel); the arrow marks the catheter (right panel) - case 1.

hepatic metastases of colorectal cancer in total was investigated. The mean local control rate of all groups was 34 months(according to Kaplan-Meier assessment) whereby it significantly increased - as expected - with higher dose of radiation (25.6, 31.1 and 46.6 months, respectively). Mohnikeet al [84]. Showed a significantly better survival in 83 patients with HCC who had undergone prospective BT compared (by "matched-pair" analysis) with a group of patients with no radiation.

A further study reported on local 1- and 2-years control rates of $93 \%$ and $82 \%$ in secondary and $86 \%$ and $79 \%$, respectively, in primary solitary but unrespectable malignant neoplasms of the lung [85].

\section{Representative Case Reports}

\section{Case 1 (Figures 8-11)}

Medical history: 74-year old male patient with symptomatic metastasis of rectal cancer localized at the left iliac muscle.

10/2006 - deep anterior resection with TME and creation of a protective ileostoma, pT3a pN1 (14/81) cM0 R0 G2

Until 04/2007 - adjuvant radio chemotherapy with 5-FU ad 54Gy 
followed by 4 cycles of Chemotherapy alone with 5-FU

06/2007 - Recreation of gastrointestinal passage

01/2011 -Recurrent tumor growth at the left iliac muscle

Until04/2012 - 2nd-and 3rd-line chemotherapy

- Result: partial response

- Side effect: polyneuropathy and -foot syndrome

05/2012 -local radiotherapy because of pain ad $14.4 \mathrm{~Gy}$ - result: "Stable disease"(SD)

12/2012 -subsequently SD but increasing pain.

Therapeutic decision-making after interdisciplinary board presentation of the case: Surgical intervention aiming for a possibly radical but function-preserving tumorreduction and following local BT taking into account the previous radiation exposition and dose.

Further clinical course:

03-04/2013 - Tumor debulking+ postoperative fractionated iBT ad 18/6Gyat the R2 site

$10 / 2013$ - distinct reduction of the treated tumor volume and the pain, advanced tumor growth at the peripheral site of the treated tumor region

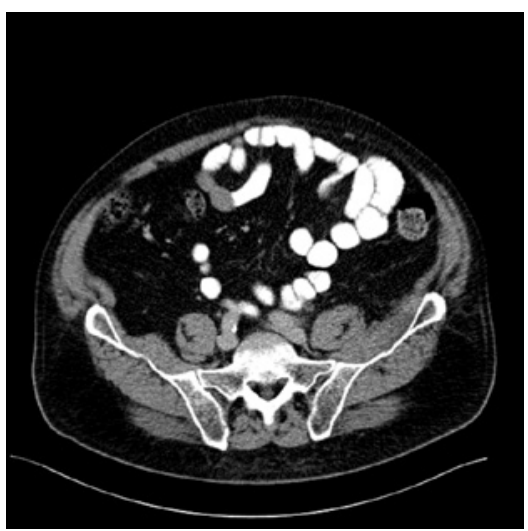

Figure 11: Follow-up CT scans 3 months postinterventionally: Result of PETguided iBT - case 1.

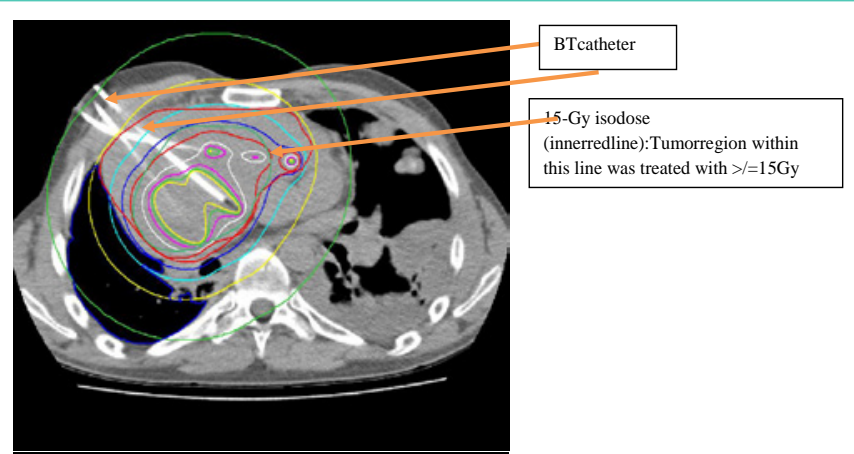

Figure 12: СT transversals scan: Catheter and isodose lines (orange arrows) - case 2; planning software: Oncentra-Brachy modul; radiation: micro Selectron-HDR (digital) After loader, v3-Iridium-192 source (Fa. Elekta; Veenendal, Netherlands).

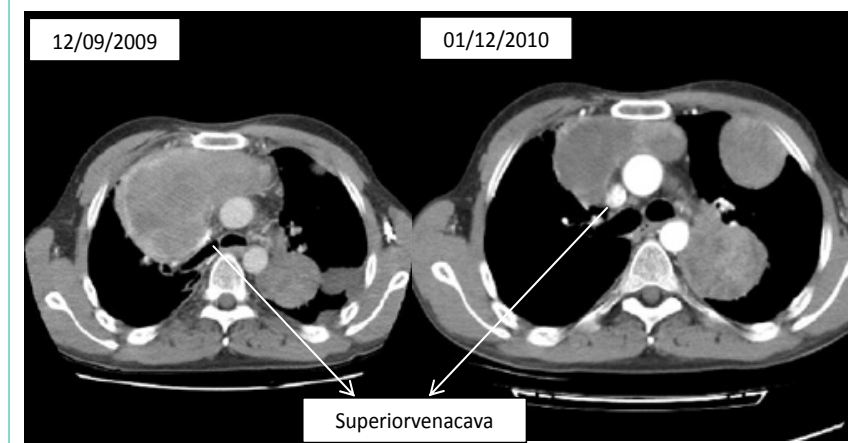

Figure 13: CT transversal scans:

Left panel: CT scan before iBT with profound compression of superior vena cava,

Right panel: CT scan 3 weeks after iBT showing a significant reduction of tumor volume; consecutively, vena cava without any further compression case 2.

11/2013 - repeated, locally restricted one-time iBT taking into account the exposure due to pre-radiation ad 13Gy

08/2014 - Recurrent tumor growth within the surrounding tissue with infiltration of the rightileal

Bone: "Involved-field" EBRT taking into account the exposure due to pre-radiation ad 20/4Gy.

Result: At the time of increasing symptoms, patient denied repeated chemotherapy because of the persisting side effects. Since distant metastases could be excluded, a local ablation appeared reasonable. High-dose iBT allowed - after surgical R2 tumor resection - a completion of ablation.

Because of the 2-times prior percutaneous charge, repeated EBRT would have been associated with significantly higher risk of a damage of surrounding risk structures (OAR) and lower effectivity (fractionation).

Furthermore, locally restricted iBT allowed a repeated radiation therapy of the neighboring regions which showed metastases during further clinical course.

Final assessment: Overall, a distinct improvement of the partially considerable symptoms could be achieved by an interdisciplinary coordinated local therapy.

\section{Case 2 (Figures 10-12)}

Medical history: 33-years old patient with superior vena-cava compression syndrome due to a synovial cell sarcoma with metastases in the lung and lymph nodes, G III.

09/2004 Solitary primary tumor lesion at the left heel leading to amputation of the left calf

12/2005 Primary diagnosis of pulmonary metastases leading to right-sided segmental resection

11/2005-02/2006 3 cycles of chemotherapy with Ifosfamid/Adriamycin

02/06 Stereotactic RT ad 30Gy per single dosesof 10Gybecause of recurrent tumor growth within the left paracardial region 
$04 / 2006$

Initiation of chemotherapy with Trofosfamid

08/2008 Continuation of the palliative chemotherapy because of recurrent pulmonary tumor growth

11/2009 Restaging using imaging as part of the diagnostic of spontaneous pneumothorax-detection of extended pulmonary and mediastinal metastases, in particular, at the upper right thoracic inlet

12/2009 Development of a superior vena-cava compression syndrome.

Therapeutic decision-making after interdisciplinary board presentation of the case:

Two options were discussed:

a) Percutaneous radiation ad 30/3 Gy $5 x$ a week resulting in a final duration of the therapy of 2 weeks;

b) CT-guided one-time iBT of the tumor parts close to vena cava ad $15 \mathrm{~Gy}$, duration of therapy including post interventional clinical follow-up observation: $4 \mathrm{~d}$.

Since the patient favored a possibly short hospital stay, option (b) was performed. Taking into account the OAR, the tumor parts close to the vena cava, which caused superior vena-cava compression syndrome, were treated with radiotherapy of a surrounding dose (D100) of 9.5Gy (D95: 15Gy, D90: 16Gy).

Result: After three days, reduction of the symptoms of the superior vena-cava compression syndrome; patient was discharged after four days. Control CT scan approximately four weeks post radiation revealed a favorable PR with a free patency through the superior vena-cava segment, radiogenic side effect were not seen, in particular, no radiation-induced pneumonitis.

Final assessment: This case indicates the benefit of an only cytoreductive interstitial BT. In an overall limited prognosis due to total tumor burden, a prompt and effective control of the partially severe symptoms could be achieved.

\section{Outlook (Further in Near Future Available Approaches and Procedures)}

Since February 2012, a further approach of "short brachytherapy" has been offered, which is - however - not considered a mode of classical BT but finally based on the emission of a low-energy X-ray, it preserves surrounding structures and organs effectively. The device is called INTRABEAM (Carl Zeiss Meditec AG, Oberkochen, Germany).

Primarily, patients with breast cancer benefit from it [86,87], further indications are under close examination, among others intraoperative radiation of the tumor bed in recurrent tumor growth of neoplasms of the pelvis.

In addition, since2014 insertion of radioactive seeds in locally restricted tumor lesions of the prostate has been offered. The characteristic feature of the seeds is the slow emission of energy. This procedure is, therefore, called "Low-Dose-Rate brachytherapy"(LDR). Tumor-damaging dose of energy is continuously emitted over a time period of approximately 3 months. From a radiobiological perspective, this procedure preserves risk structures (such as rectum, urinary bladder) better than conventional EBRT would be able to

\section{Disadvantages, Side Effects, Complications of Brachytherapy and their Management}

A potential disadvantage of $\mathrm{iBT}$ is the invasiveness, which however - is minimal but can be considered a still existing risk for bleedings, infections or -in the treatment of pulmonary metastasesfor pneumothorax. Tseliset al. investigated the rate of acute side effects after hypo fractionated iBT of unrespectable primary and secondary hepatic metastases close to the hilus in 41 patients. The incidence for grade-III/-IV side effects was 5\% [88].

A comparable result indicating a rate of severe grade-III/-IV side effects lower than $5 \%$ was reported by Mohnikeet al. (manuscript submitted) in a retrospective analysis of a patient cohort of 192 patients with BT of hepatic neoplasms. These patients underwent depending on the tumor entity single doses spanning from 15 to 20Gy.

Taken together, the retrospective studies as well as the data obtained in prospective studies at Magdeburg, Berlin and Offenbach (Germany each; as cited above) indicate that iBT can be considered locally ablating tumor therapy with high effectivity and a low rate of side effects if the known and newly validated dose limitations are carefully respected [89-91].

By means of specific institutional "standard operating procedures", which define clearly preparation, interventional procedure and post interventional monitoring as well as risk management, the majority of complications has been micro invasively and conservatively treated since 2006 .

\section{Discussion}

The value of radiotherapy established until today as part of curative and palliative tumortherapy strategies cannot longer denied even if the use of it is possibly ranked inferior to best supportive care and beyond primary therapeutic concepts in a certain proportion of oncologists.

While the options of percutaneous radiation techniques are known and present as well as discussed in the media and tumor board conferences throughout the country, BT is rather underestimated.

However, advantages are obvious in case of a clearly defined indication, e.g.

- High, locally applicable tumor-damaging dose,

- Better preservation of the surrounding OAR by a steep dose gradient (and)

- Shorter hospital stay, since over a few days a sufficient dose can be applied.

In the mean time, pro- and retrospective studies provided evidence that in part more than a palliative effect can be achieved. In particular, patients with metastases of colorectal origin [83] but also those with locally restricted HCC $[34,84]$ may benefit from this approach with a prolongation of survival. A basic prediction for the broad use of brachytherapeutic interventions is an interdisciplinary collaboration. 
-Adapted to patients 'needs and tumor-specific finding(s),

-Related to the specific tumor entity and stage,

-According to established therapeutic experiences and proven modi of radiation to exhaust a sufficient, (neo-) adjuvant, additive or palliative therapeutic effect.

In addition, it has been shown that in many cases BT can be considered-from the perspective of health economy-a cost-effective but despite this a highly effective treatment alternative in the age of a rather increasingly cost-intensive tumor therapy, which broadens the spectrum of radio oncology.

\section{Conclusion}

Gold standard of local ablation was and is surgical resection. A certain percentage of (oligo-) metastasized patients can not undergo surgical intervention or tumor mass is unrespectable from a functional and tumor biological perspective. These patients can nevertheless treated with local ablation since in addition to surgical intervention (resection), there has been a number of non- and minimally invasive techniques available. These procedures can be subdivided into thermo-, chemo- and radio-ablading methods and have been multiply proven in prospective and retrospective studies with regard to safety, effectivity and side effect rate [92-100].

RFA is currently the best validated method, which - if the metastasis is not bigger than $3 \mathrm{~cm}$ in diameter - can be, in particular, in the liver, and is considered a reasonable alternative to surgical resection resulting in a very similar, i.e., low tumor recurrency rate (5.5 vs. $6 \%$ per lesion). In larger metastases, surgical resection is superior (7.4 vs. $14.5 \%$ ) [101]. Under these circumstances iBT used in radiotherapy routine for decades can reasonably add the spectrum of indications and therapeutic modalities.

Data obtained in phase-II studies showed that in case of sufficient tumor-surrounding dose application, local tumor recurrence rate is approximately.

- $6.5 \%$ in liver metastases of breast cancer [82],

- $5 \%$ in liver metastases of colorectal origin [83] (and)

- $9 \%$ and 14 / $7 \%$ in primary and secondary malignant neoplasms of the lung [85].

In addition, Mohnikeet al. [32] was able to demonstrate a significant improvement of survival in patients with versus cases without BT of locally advanced HCC manifestation.

A successful iBT requires a close interdisciplinary cooperation between radio oncologists, interventional radiologists and all oncological disciplines in medicine.

Finally, the clue for a broad use of all available oncological therapeutic options is their profound knowledge on

-the appropriate indications and possible complications,

-the indicated differential therapy,

-Methodological strengths and weaknesses obtained from individual

* Case-based experiences (and)
${ }^{*}$ Case presentations at tumor board conferences.

\section{References}

1. Röntgen WC. Ueber eine neue Artvon Strahlen. Vorläufige Mittheilung. Sonderabbdruck aus den Sitzungsberichten der Würzburger Physik.-medic. Gesellschaft 1895, Verlag: Stahel'sche K. Hof- und Universitätsbuch- und Kunsthandlung oder 2. Aufl. Wurzburg. 1896.

2. Becquerel $\mathrm{H}$. Emissions of the new radiations by metallic uranium. Comp Rend Acad Sci. 1896; 122:1086.

3. Becquerel $H$, Curie $P$. Action physiologiques des rayons du radium. $C R$ AcadSci Gen.1901; 132: 1289-1291.

4. Curie $P$, Curie $M$. Sur une substance nouvelle radio-active contenuedans la pechblende. C R AcadSci Gen. 1898; 127: 175-178.

5. Freund L. Ein mit Röntgenstrahlen behandelter Fall von Naevuspigmentosispiliferus. Wien Med Wochensch. 1897; 10: 428-433.

6. Morton R. Treatment by Roentgen- and radium rays. BrMedJ. 1904; 1: 941 944.

7. Pusey WA Caldwell EW. The practical applications of the Roentgen rays in therapeutics and in diagnosis. $2^{\text {nd }}$ edn Philadelphia: Saunders, 1904.

8. Wickham L. Degrais P. Die Radiumbehandlung des Krebses. Fortschritte auf dem Gebiet der Röntgenstrahlen. 1910; 16: 73.

9. Wickham L, Degrais P.Kanndas Radium der Chirurgie bei derBehandlungmalignerTumorenDiensteleisten? Strahlentherapie. 1913; 3 : 457-472.

10. Wickham L, Degrais P. Radium as employed in the treatment of cancer, angiomata, keloids, local tuberculosis and other affectations. New York: Paul B. Hoeber; 1913.

11. Goldberg SW, London ES. Zur Frage der Beziehungen zwischen Bequerelstrahlen und Hautaffektionen. Dermatol Z. 1903; 10: 457-462.

12. Strebel H. Vorschläge zur Radium Therapie. Dtsch Med Z.1903; 24: 11451146.

13. Abbé R. The status of radium. Med Rec (New York).1904; 65: 356.

14. Strebel H. Der gegenwärtige Stand der Radiumforschung. Zeitschrift für neuere physiologische Medizin. 1908; 15: 180-183.

15. Wolff KD, Book F, Beck J, et al. S3 Leitlinien Mundhöhlenkarzinom Leitlinienprogramm Onkologie der AWMW.

16. Bartelink H, Roelofsen F, Eschwege F, Rougier P, Bosset JF, Gonzalez DG, et al. Concomitant radiotherapy and chemotherapy superior to radiotherapy alone in the treatment of locally advanced anal cancer: results of phase III randomized trial of the EORTC Radiotherapy and Gastrointestinal Cooperative Groups. J ClinOncol.1997; 15: 2040-2049.

17. Grimm P, Billiet I, Bostwick D, et al. Comparative analysis of prostatespecific antigen free survival outcomes for patients with low, intermediate and high risk prostate cancer treatment by radical therapy. Results from the Prostata Cancer Results Study Group. BJU Int. 2012; 109: 22-29.

18. Colombo N, Carinelli S, Colombo A, et al. on behalf of the ESMO Guidelines Working Group. Cervical cancer: ESMO Clinical Practice Guidelines for diagnosis, treatment and follow-up. Ann Oncol. 2012; 23: 27-32.

19. Rentsch M, Winter H, Bruns CJ, et al. Cyberknife ${ }^{\circledR}-$ Chirurgie mit dem Strahlenmesser: eine neue Behandlungsalternative für Patienten mit inoperablen Metastasen. ZentralbIChir. 2010; 135: 175-180.

20. Dudeck O, Weigt J, Schubert D, et al. Deutsche Akademie für Mikrotherapie (DAfMT) - moderne bildgeführte, minimalinvasive, mikrotherapeutische, teils interdisziplinäre Therapieansätze zur klinischen Ausbildung \& für die Praxis (Nachlese zum Eröffnungssymposium zu Ansatz, Zielstellung, Spektrum \& Umsetzungskonzepten). Zentralbl Chir. 2011; 136: 634-635.

21. Damm R, Seidensticker R, Ricke J, et al. Interventional Radiological Procedures in the Therapy for Colorectal Liver Metastases. ZentralbIChir. 2013; 138: 76-83. 
22. Bleicher RJ, Allegra DP, Nora DT, et al. Radiofrequency ablation in 447 complex unresectable liver tumors: lessons learned. Ann SurgOncol. 2003 10: 52-58.

23. Ruers $\mathrm{T}$, Punt $\mathrm{CJ}$, van Coevorden $\mathrm{F}$, et al. Radiofrequency ablation combined with systemic treatment versus systemic treatment alone in patients with non-resectable colorectal liver metastases: a randomized EORTC Intergroup phase II study (EORTC 40004): Ann Oncol. 2012; 3: 2619-2626.

24. Lee DH, Lee JM, Lee JY, et al. Radiofrequency ablation of hepatocellular carcinoma as first-line treatment: long-term results and prognostic factors in 162 patients with cirrhosis. Radiology. 2014; 270: 900-909.

25. Cucchetti A, Piscaglia F, Cescon M, et al. An explorative data-analysis to support the choice between hepatic resection and radiofrequency ablation in the treatment of hepatocellular carcinoma. Dig Liver Dis. 2014; 46: 257-263.

26. Ricke J, Wust P, Wieners G, et al. Liver malignancies: CT-guided interstitial brachytherapy in patients with unfavorable lesions for thermal ablation. J VascIntervRadiol. 2004; 15: 1279-1286.

27. Collettini F, Golenia M, Schnapauff D, et al. Percutaneous computed tomography-guided high-dose-rate brachytherapy ablation of breast cance liver metastases: Initial experience with 80 lesions. J VascIntervRadiol. 2012; 23: 618-626.

28. Bretschneider T, Peters N, Hass $\mathrm{P}$, et al. Update interstitielle Brachytherapie. Radiologe. 2012; 52: 70-3.

29. Hass $P$, Bretschneider T, Mohnike K. CT-guided brachytherapy. Interventionelle Rad Scan. 2013; 2: 163-180.

30. Schnapauff D, Denecke T, Grieser C, et al. Computed Tomography-Guided Interstitial HDR Brachytherapy (CT-HDRBT) of the Liver in Patients with Irresectable Intrahepatic Cholangiocarcinoma. CardiovascInterventRadiol. 2012; 35: 581-587.

31. Peters N, Wieners G, Pech M, et al. CT-guided interstitial brachytherapy of primary and secondary lung malignancies. Results of a prospective phase II trial. StrahlentherOnkol. 2008; 184: 296-301.

32. Mohnike K, Wieners G, Pech M, et al. Image-guided interstitial high-doserate brachytherapy in hepatocellular carcinoma. Dig Dis. 2009; 27: 170-174.

33. Ricke J, Wust P. Computed Tomography-Guided Brachytherapy for Live Cancer. SeminRadiatOncol. 2011; 21: 287-293.

34. Collettini F, Schnapauff D, Poellinger A, et al. Hepatocellular carcinoma computed-tomography-guided high-dose-rate brachytherapy (CT-HDRBT) ablation of large $(5-7 \mathrm{~cm})$ and very large $(>7 \mathrm{~cm})$ tumours. EurRadiol. 2012 22: 1101-1109.

35. Dominici $\mathrm{H}$, Barcat J. Des modifications histologigues determines par le rayonnement du radium. Arch elec med. 1907; 15: 835-836.

36. Forsell G. Übersicht über die Resultate der Krebsbehandlung am Radiumhemmet in Stockholm 1910-1915. FortschrRontgenstr. 1917; 25 : 142-149.

37. Coliez R. Les bases physiques de l'irradiation du cancer du col uterinpar la curietherapieet la radiotherapie. J Radiol. 1923; 7: 201-216.

38. Heyman J. Radiological or operative treatment of cancer of the uterus ActaRadiol. 1927; 8: 363-409.

39. Lacassagne A. Results of the treatment of cancer of the cervix uteri. Br Med J. 1932; 2: 912-913.

40. Heyman J. The radiumhemmet method of treatment and results in cancer of the corpus uteri. JObstet Gynecol. 1936; 43: 655-666.

41. Knocke TH, Tatzreiter G, Baldas M, et al. Results of postoperative irradiation in Patients with high risk endometrial carcinoma. RadiotherOncol. 1998; 48 66.

42. Creutzberg CL, van Putten WL, Koper PC, et al. Surgery and postoperative radiotherapy versus surgery alone for patients with stage-I endometrial carcinoma: multicenter randomized trial. PORTEC Study Group. Postoperative Radiation Therapy in Endometrial Carcinoma. Lancet. 2000; 355: 1404-1411.
43. Klopp A, Smith, BD, Alektiar K, et al. The role of postoperative radiation therapy for endometrial cancer: Executive Summary of an American Society for Radiation Oncology evidence-based guideline. Practical Radiation Oncol. 2014; 4: 137-144.

44. Thomas G. Improved treatment for cervical cancer - Concurrent chemotherapy and radiotherapy. N Engl J Med. 1999; 340: 1198-1200.

45. Haie-Meder C, Potter R, Van Limbergen E, et al. Recommendations from Gynaecological (GYN) GEC-ESTRO Working Group (I): concepts and terms in 3D image based 3D treatment planning in cervix cancer brachytherapy with emphasis on MRI assessment of GTV and CTV.RadiotherOncol. 2005 74: $235-245$.

46. Chyle V, Zagars GK, Wheeeler JA, et al. Definitive radiotherapy for carcinoma of the vagina: outcome and prognostic factors. Int J RadiatOncolBiol Phys. 1996; 35: 891-905.

47. Tewari KS, Cappuccini F, Puthawala AA, et al. Primary invasive carcinoma of the vagina: Treatment with interstitial brachytherapy. Cancer. 2001; 91: 758-770.

48. Dimopoulos J, Schmid M, Berger D et al. MRI-guided Brachytherapy with external beam therapy plus chemotherapy for the treatment of locally advanced vaginal cancer. RadiothOncol. 2009; 1: 51.

49. Kumar PP, Good RR, Scott JC. Techniques for management of vulvar cancer by irradiation alone. Radiat Med. 1988; 6: 185-191.

50. Pohar S, Hoffstetter S, Peiffert D, et al. Effectivenes of brachytherapy in treating carcinoma of the vulva. Int J RadiatOncolBiol Phys. 1995; 32: 14551460 .

51. Seeger AR, Windschall A, Lotter M, et al. The role of interstitiell brachytherapy in the treatment of vaginal and vulvar malignancies. StrahlentherOnkol. 2006; 182: 142-148

52. Paterson R, Parker HM. A dosage system for interstitial radium therapy. $\mathrm{Br}$ J Radiol. 1938; 1: 252-340.

53. Meredith WJ. Radium Dosage: The Manchester System. Edinburgh: Livingston. 1967.

54. Henschke U, Hilaris BS, Mahan GD. Afterloading in interstitial and intracavitary radiation therapy.Am J Roentgenol.1963; 90: 386-395.

55. Wolff KD, Bootz F, Beck J, et al. Leitlinienprogramm Onkologie / S3-Leitlinie Mundhöhlenkarzinom. September 2012; AWMF-Register 007-1000L, Version 2.0.

56. Al-Sarraf M, Pajak TF, Byhardt RW, et al. Postoperative radiotherapy with concurrent cisplatin appears to improve loco regional control of advanced respectable head and neck cancers: RTOG 88-24. Int J RadiatOncolBiol Phys. 1997; 37: 777-782.

57. Pignon JP, Bourhis J, Domenge $\mathrm{C}$, et al. Chemotherapy added to locoregional treatment for head and neck squamous cell carcinoma: Three metaanalyses of updated individual data. MACH-HNC Collaborative Group: Meta-Analysis of Chemotherapy on Head and Neck Cancer. Lancet. 2000; 355: 949-955.

58. Pignon JP, le Maître A, Maillard E, et al. on behalf of the MACH NCCollaborative Group. Meta-analysis of chemotherapy in head and neck cancer (MACH-NC): An updateon 93 randomised trials and 17346 patients. RadiotherOncol. 2009; 92: 4-14.

59. Zelefsky MJ, Zimberg SH, Raben A, et al. Brachytherapy for locally advanced and recurrent lymph node metastases. J Brachytherapy Int. 1998; 14: $123-130$.

60. Gerbaulet A, Maher M. Brachytherapy in the treatment of head and neck cancer. In: Joslin CAF, Flynn A, Hall EJ (eds). Principles and practice of brachytherapy 2001. London: Arnold; 284-295.

61. Mazeron JJ, Ardiet JM, Haie-Meder C, et al. GEC-ESTRO recommendations for brachytherapy for head and neck squamous cell carcinomas. RadiotherOncol. 2009; 91: 150-156.

62. Takehiro I, Toshihiko I, Teruki T, et al. Phase III trial of high and low dose rate interstitial radiotherapy for early oral tongue cancer. Int J RadiatOncolBiol Phys. 1996; 36: 1201-1204. 
63. Grabenbauer GG, Rödel C, Brunner T, et al. Interstitial brachytherapy with Iridium-192 low-dose-rate in the treatment of primary and recurrent cance of the oral cavity and oropharynx. Review of 318 patients treated between 1985 and 1997. StrahlentherOnkol. 2001; 177: 338-344.

64. Guinot JL, Arribas L, Vendrell JB, et al. Prognostic factors in squamous cell lip carcinoma treated with high-dose-rate Brachytherapy. Head Neck. 2013 36: $1737-1742$.

65. Nag S, Cano ER, Demanes DJ, et al. for the American Brachytherapy Society. The American Brachytherapy Society recommendations for highdose-rate brachytherapy for head-and-neck carcinoma. Int JRadiation OncologyBiol Phys. 2001; 50: 1190-1198.

66. Syed AM, Feder BH, George FW $3^{\text {rd }}$, et al. Iridium-192 afterloaded implant in the retreatment of head neck cancers. Br J Radiol.1978; 51: 814-820.

67. Strnad V, Geiger M, Lotter M, et al. Role of brachytherapy for head and neck cancer: retreatment in previously irradiated area. Brachytherapy. 2003; 2 158-163.

68. Narayana A, Cohen GN, Zaider $M$, et al. High-dose-rate interstitia brachytherapy in recurrent and previously irradiated head and neck cancers preliminary results. Brachytherapy. 2007; 6: 157-163.

69. Rudzianskas V, Inciura A, Juozaityte $E$, et al. Reirradiation of recurrent head and neck cancer using high-dose-rate brachytherapy. ACTA otorhinolaryngologicaitalica. 2012; 32: 297-303.

70. Tselis N, Ratka M, Vogt HG, et al. Hypofractionated accelerated CT-guided interstitial 192Ir-HDR-Brachytherapy as reirradiation in inoperable recurren cervical lymphadenopathy from head and neck cancer. RadiotherOncol. 2011; 98: 57-62

71. Nag S. Principles and practice of brachytherapy 1997. New York: Futura Publishing Company.

72. Speiser BL, Mould RF. Brachytherapy for the $21^{\text {st }}$ century. Veenendaal The Netherlands: Nucletron International. 1998.

73. GejermanG, Mullokandov EA,Bagiella E, et al. Endobronchial brachytherapy and external-beam radiotherapy in patients with endobronchial obstruction and extrabronchial extension. Brachytherapy. 2002; 1: 2004-2010.

74. Morris CD, Budde JM, Godette KD, et al. Palliative management of malignant airway obstruction. Ann Thorac Surg. 2002; 74: 1928-1933.

75. Manali ED, Stathopoulos GT, Gildea TR, et al. High dose-rate endobronchia radiotherapy for proximal airway obstruction due to lung cancer: 8-year experience of a referral center. Cancer BiotherRadiopharm. 2010; 25: 207 213.

76. Hareyama M, Nishio M, Kagami $\mathrm{Y}$, et al. Intracavitary brachytherapy combined with external beam irradiation for squamous cell carcinoma of the thoracic esophagus. Int J RadiatOncolBiol Phys. 1992; 24: 235-240.

77. Lettmaier S, Strnad V. Intraluminal brachytherapy in oesophagea cancer: defining its role and introducing the technique. J Contemporary Brachytherapy. 2014; 6: 236-241.

78. Válek V, Kysela P, Kala Z, et al. Brachytherapy and percutaneous stenting in the treatment of cholangiocarcinoma: a prospective randomised study. Eur J Radiol. 2007; 62: 175-179.

79. Shinohara ET, Guo M, Mitra N, et al. Brachytherapy in the treatment of cholangiocarcinoma. Int J RadiatOncolBiol Phys. 2010; 78: 722-728.

80. Shrivastava SK, Engeneer R, Mahantshetty U, et al. External beam radiotherapy and interstitial brachytherapy with or without chemotherapy in the conservative treatment of anal carcinoma. Brachytherapy. 2008; 7: 102.

81. Ricke J, Wust P, Stohlmann A, et al. CT-guided interstitial brachytherapy of liver malignancies alone or in combination with thermal ablation: phase I-II results of a novel technique. Int J RadiatOncolBiol Phys. 2004; 58: 14961505 .

82. Wieners G, Mohnike K, Peters N, et al. Treatment of hepatic metastases of breast cancer with CT-guided interstitiell brachytherapy - A phase II-study. RadiotherOncol. 2011; 100: 314-319.
83. Ricke J, Mohnike K, Pech M, et al. Local response and impact on survival after local ablation of liver metastases from colorectal carcinoma by computed tomography-guided high-dose-rate brachytherapy. Int J RadiatOncolBiol Phys. 2010; 78: 479-485.

84. Mohnike K, Wieners G, Schwartz F, et al. Computed tomography-guided high-dose-rate brachytherapy in hepatocellular carcinoma: Safety, efficacy and effect on survival. Int J Radiation Oncology Biol Phys. 2010; 78: 172 179.

85. Tselis N, Ferentinos K, Kolotas C, et al. Computed tomography-guided interstitial high-dose-rate brachytherapy in the local treatment of primary and secondary intrathoracic malignancies. J ThoracOncol. 2011; 6: 545-552.

86. Vaidya JS, Joseph DJ, Tobias JS, et al. Targeted intraoperative radiotherapy versus whole breast radiotherapy for breast cancer (TARGIT-A trial): an international, prospective, randomized, non-inferiority phase 3 trial. Lancet. 2010; 376: 91-102

87. Kraus-TiefenbacherU, Hermann B, Siebenlist, T et al. Long-term toxicity of an intraoperative radiotherapy boost using low energy $x$-rays during breastconserving surgery. Int J RadiatOncolBiol Phys. 2006; 66: 377-381.

88. Tselis N, Chatzikonstantinou G, Kolotas C, et al. Computed tomographyguided interstitial high dose rate brachytherapy for centrally located liver tumours: a single institution study. EurRadiol. 2013; 23: 2264-2270.

89. Emami B, Lyman J, Brown A, et al. Tolerance of normal tissue to therapeutic radiation Int J RadiatOncolBiol Phys.1991; 21: 109-122.

90. Streitparth F, Pech M, Bohmig M, et al. In vivo assessment of the gastric mucosal tolerance dose after single fraction, small volume irradiation of liver malignancies by computed tomography-guided, high-dose-rate brachytherapy. Int J Radiat Oncol Biol Phys. 2006; 65: 1479-1486.

91. Marks L, Yorke ED, Jackson E, et al. Use of normal tissue complication probability models in the clinic. Int J RadiatOncolBiol Phys. 2010; 76: 10-19.

92. Sato KT, Lewandowski RJ, Mulcahy MF, et al. Unrespectable chemo refractory liver metastases: radioembolization with $90 \mathrm{Y}$ microspheres-safety, efficacy, and survival. Radiology. 2008; 247: 507-515.

93. Ricke J, Großer O, Amthauer H. Y90-radioembolization of lung metastases via the bronchial artery: a report of 2 cases. CardiovascInterventRadiol. 2013; 36:1664-1669.

94. Lee DH, Lee JM, Lee JY et al. Radiofrequency ablation of hepatocellular carcinoma as first-line treatment: long-term results and prognostic factors in 162 patients with cirrhosis. Radiology. 2014; 270: 900-909.

95. Weis S, Franke A, Mössner J, et al. Radiofrequency (thermal) ablation versus no intervention or other interventions for hepatocellular carcinoma Cochrane Database Syst Rev. 2013.

96. Pech M, Wieners $G$, Freund $T$, et al. MR-guided interstitial laser thermotherapy of colorectal liver metastases: efficiency, safety and patients survival. Eur J Med Res. 2007; 12: 161-168.

97. Bruix J, Sala M, Llowet JM. Chemoembolisation for hepatocellular carcinoma. Gastroenterology. 2004; 127: 179-188.

98. Schefter TE, Kavanagh BD. Radiation therapy for liver metastases. SeminRadiatOncol. 2011; 21: 264-270.

99. Navarria P, Ascolese AM, Tomatis $S$, et al. Stereotactic body radiotherapy (SBRT) in lung oligometastatic patients: role of local treatments. RadiatOncol. 2014; 9: 91.

100. Hass P, Mohnike K. Extending the frontiers beyond thermal ablation by RFA SBRT, Brachytherapy, SIRT. Viszeralmedizin. 2014; 30: 245-252.

101.Tanis E, Nordlinger B, Mauer M, et al. Local recurrence rates after radiofrequency ablation or resection of colorectal liver metastases. Analysis of the European Organisation for Research and Treatment of Cancer \#40004 and \#40983. Eur J Cancer. 2014; 50: 912-919. 